Pacific Journal of Mathematic 


\title{
THE ASYMPTOTIC EEHAVIOR OF NORMS OF POWERS OF ABSOLUTELY CONVERGENT FOURIER SERIES
}

\author{
DenNis M. GIRARD
}

Let $f(t)$ have an absolutely convergent Fourier series $f(t)=\sum a_{k} e^{i k t}$ and set $\|f\|=\sum\left|a_{k}\right|$. In this paper we will study the asymptotic behavior of $\left\|f^{n}\right\|$ as $n \rightarrow \infty$.

Theorem. Let $f$ be absolutely continuous and let $f^{\prime}$ be of bounded variation on the real line modulo $2 \pi$. Let $f(0)=$ 1 but $|f(t)|<1$ for $t \neq 0$ and suppose that for $t$ near 0 , $f(t)=\phi\left(e^{i t}\right)$ where $\phi$ is defined and analytic near $z=1$. Define the parameters $\alpha, p, q, \mathbf{A}$ and $\beta$ as follows

$$
\begin{aligned}
\alpha & =\phi^{\prime}(1) \\
\phi(z) & =z^{\alpha}+A i^{p}(z-1)^{p}+o(1)(z-1)^{p}, z \rightarrow 1(A \neq 0) \\
\left|\phi\left(e^{\imath t}\right)\right| & =1-\beta t^{q}+o\left(t^{q}\right), t \rightarrow 0(\beta \neq 0) .
\end{aligned}
$$

Then, (a) for $p \neq q$

$$
\left\|f^{n}\right\| \sim(2 / \pi)^{1 / 2+\delta(p)} q^{-1}[p(p-1)]^{1 / 2} \Gamma(p / 2 q)|A|^{1 / 2} \beta^{-p / 2 q} n^{(1-p / q) / 2}
$$

where $\delta(p)=0$ if $p$ is even and, $=1$ if $p$ is odd; (b) for $p=q$

$$
\lim _{n \rightarrow \infty}\left\|f^{n}\right\|=(1 / 2 \pi)\|\hat{F}\|_{1}
$$

where $\hat{F}$ is the Fourier transform of $F(t)=\exp \left(A t^{p}\right)$.

The following results about these parameters are known and easily verifiable: $p$ and $q$ are positive integers, $2 \leqq p \leqq q$, $q$ is even, $\beta>0, \operatorname{Re} A \leqq 0 ; p=q$ if and only if $\operatorname{Re} A \neq 0 ; p=q$ implies $\beta=-\operatorname{Re} A$;

$$
\phi\left(e^{i t}\right)=\exp \left[i \alpha t+A t^{p}+\mathcal{O}\left(t^{p+1}\right)\right], t \rightarrow 0 \text { if } p=q,
$$

and

$$
\begin{aligned}
\phi\left(e^{i t}\right)= & \exp \left[i \alpha t+(-1)^{p} A t^{p}+i \sum_{r=p+1}^{q} c_{r} t^{r}-\beta t^{q}\right. \\
& \left.+\mathcal{O}\left(t^{q+1}\right)\right], \text { as } t \rightarrow 0, c_{r} \text { real, if } p \neq q .
\end{aligned}
$$

We outline in $\S 5$ how it is possible to relax the condition of analyticity at $t=0$ and replace it with conditions (1) and (2) where the $\mathcal{O}$ terms satisfy certain smoothness conditions.

G. W. Hedstrom proved in 1966 that under these same hypotheses, there exist two constants $c, C$ such that $c<$ $\left\|f^{n}\right\| n^{-(1-p / q) / 2}<C$

1. Introduction. The classical result of this type is that $\lim _{n \rightarrow \infty}\left\|f^{n}\right\|^{1 / n}=1$, but much better estimates, namely $\left\|f^{n}\right\|=\infty(n)$, $n \rightarrow \infty$ and even $\left\|f^{n}\right\|=\infty(\sqrt{n}), n \rightarrow \infty$ were relatively easy to obtain [1], [5], [6]. It is also known that this last estimate is the best 
possible. More precise estimates for $\left\|f^{n}\right\|$ were separately sought for those functions satisfying respectively points,

(i) $|\phi(z)|$ attains its maximum on $|z|=1$ at finitely many

(ii) $|\phi(z)|=1$ for $|z|=1$.

It is known that if $\phi(z)$ satisfies (ii) and is not a power of $z$, then $\left\|f^{n}\right\| \rightarrow \infty$ as $n \rightarrow \infty$ [1], and more precisely, there exist positive constants $c_{1}, c_{2}$ such that $c_{1} \sqrt{n} \leqq\left\|f^{n}\right\| \leqq c_{2} \sqrt{n}$ [6].

It was proved in [1], [3] that if $\phi(z)$ does satisfy (i), then the necessary and sufficient condition for $\left\|f^{n}\right\|=\mathscr{O}(1)$ as $n \rightarrow \infty$ is that $p=q$ at each point of maximum modulus. In the case where $p=q$ is not satisfied at each point Hedstrom [4] has shown that there exist constants $C_{1}, C_{2}$ such that $C_{1} n^{s} \leqq\left\|\phi^{n}\right\| \leqq C_{2} n^{s}$ where $s=\max (1-p / q) / 2$, the maximum being taken over all points where $p \neq q$. Further developments and connections with the work of Kahane and Leibenson can be found in Hedstrom's paper where he considers the more general case when $f(t)$ has an absolutely convergent Fourier series. Connections with the conformal invariance of peripheral convergence can be found in a paper by Bajsanski [2] and a recent thesis by Whitford [9]. The main results of Bajsanski, Clunie, and Vermes were rediscovered and appear in a recent paper by Newman [7]. In connection with this paper in $\S 4$ we discuss some partial results concerning the behavior of $\left\|f^{n}\right\|$ when $|f|$ has several points of maximum on $[-\pi, \pi]$.

2. Preliminary lemmas. We give in this section some lemmas which will be needed in the proof of the theorem. The proof of the following lemma is explicitly contained in the proof of Lemma 2.1 in [4] and so is not given.

LEMMA 1. Let $f(t)$ be absolutely continuous and suppose that $f^{\prime}(t)$ is of bounded variation and $|f(t)| \leqq 1$ for all $t$. Then, if $a_{n k}$ is the Fourier coefficient of $f^{n}(t), k=0, \pm 1, \cdots$, there are constants $C_{1}, C_{2}$ such that $\left|a_{n k}\right| \leqq C_{1} n / k^{2}$ for $|k| \geqq C_{2} n$.

Using (1) and (2) we can write

$$
f(t)=\exp \left(i \alpha t+i p(t)+G_{1}(t)\right), t \rightarrow 0
$$

where $p(t)$ is a real polynomial of degree at most $q$ and $G_{1}(t)=$ $-\beta t^{q}+G_{2}(t), G_{2}(t)=\mathscr{O}\left(t^{q+1}\right)$, as $t \rightarrow 0$. Since $f(t)$ is analytic at $t=0$, by putting

$$
z^{-\alpha} \phi(z)=\exp \left[i p[(\log z) / i]+G_{1}[(\log z) / i]\right], z \rightarrow 1,
$$


we have $f(t)=\phi\left(e^{i t}\right)$ for $t$ in some neighborhood of $t=0$, where $\dot{\phi}(z)$ is analytic in a neighborhood of $z=1$.

The following lemma generalizes Lemma 1 in [1] and plays a fundamental role in the proof of the theorem.

LEMma 2. Let $\Psi(r, t)=\operatorname{Re}\left[\log \left[\left(r e^{i t}\right)^{-\alpha} \dot{\phi}\left(r e^{i t}\right)\right]\right]$ and $r=1 \pm n^{-c}$, $c=1-(p-1) / q$. Then, if $\varepsilon_{0}$ is sufficiently small,

$$
\int_{-\varepsilon_{0}}^{\varepsilon_{0}} \exp [n \Psi(r, t)] d t=\mathcal{O}\left(n^{-1 / q}\right), n \rightarrow \infty .
$$

Proof. By Taylor's formula

$$
\Psi(r, t)=\sum_{0}^{q-1} C_{m}(r) t^{m}+C_{q}(r ; \tau) t^{q},|t|<\varepsilon_{0}
$$

where

$$
C_{m}(r)=(1 / m !) \partial^{q} \Psi(r, t) /\left.\partial t^{m}\right|_{t=0}, m=0,1, \cdots, q-1
$$

and

$$
C_{q}(r, \tau)=(1 / q !) \partial^{q} \Psi(r ; t) /\left.\partial t^{q}\right|_{t=r},|\tau|<|t|<\varepsilon_{0} .
$$

The derivatives of $C_{m}(r)$ are given by

$$
d^{n} C_{m}(r) / d r^{n}=(1 / m !) \partial^{m+n} \Psi(r, t) /\left.\partial r^{n} \partial t^{m}\right|_{t=0},
$$

but $\log z^{-\alpha} \dot{\phi}(z)=\mathscr{C}(1)(z-1)^{p}, z \rightarrow 1$ and this implies that $\Psi(r, t)=$ $\operatorname{Re}\left[\mathcal{O}(1)\left(e^{i t}(r-1)+e^{i t}-1\right)^{p}\right]$ so that the partial derivatives of $\Psi$ of order less than $p$ are zero at $r=1, t=0$. Thus $C_{m}(r)$ has a zero at the point $r=1$ of order $\geqq p-m$, for $m=0,1, \cdots, p-1$ and so $\left|C_{m}(r)\right|<C_{m}|r-1|^{p-m}$ in a sufficiently small neighborhood of $r=1$ for constants $\mathrm{C}_{m}$. In addition $\Psi(1, t)=-\beta t^{q}+\mathcal{O}\left(t^{q+1}\right)$ as $t \rightarrow 0$, so that $C_{m}(1)=0, m=p, \cdots, q-1$ and thus for $r$ sufficiently near $1,\left|\mathrm{C}_{m}(r)\right| \leqq C_{m}|r-1|, m=p, \cdots, q-1$. Furthermore, $d^{q} \Psi(1, t) /\left.d t^{q}\right|_{t=0}=$ $-q ! \beta<0$ implies that $\partial^{q} \Psi(r, t) / \partial t^{q}<-M, M>0$ for $r$ sufficiently close to 1 and $|t|<\varepsilon_{0}$, for some $\varepsilon_{0}>0$. Thus, if $r=1 \pm n^{-c}$ and $|t| \leqq \varepsilon_{0}$

$$
\Psi(r, t) \leqq \sum_{m=0}^{p-1} C_{m} n^{-(p-m) c}|t|^{m}+\sum_{m=p}^{q-1} C_{m} n^{-c}|t|^{m}-M t^{q}
$$

and so we have

$$
\int_{-\varepsilon_{0}}^{\varepsilon_{0}} \exp [\mathrm{n} \Psi(r, t)] d t \leqq n^{-1 / q} \int_{-\infty}^{\infty} \exp [Q(u)] d u,
$$

where $Q(u)=\sum_{m=0}^{p-1} C_{m} n^{1-c(p-m)-m / q}|u|^{m}+\sum_{m=p}^{q-1} C_{m} n^{1-c-m / q}|u|^{m}-M u^{q}$. But $Q(u)$ is bounded by 


$$
\sum_{m=0}^{q-1} C_{m}|u|^{m}-M u^{q}
$$

since $1-c-m / q \leqq 0$ for $m=p, \cdots, q-1$ and $1-c(p-m)-m / q \leqq 0$ for $m=0, \cdots, p-1$; the result follows.

LEMMA 3. Let $h(t)=a t+P(t)$ be a real polynomial where $a \neq 0$ and $P(t)=c_{p} t^{p}+\cdots+c_{q} t^{q}, q \geqq p \geqq 2, q$ even and let $g(t)=P^{\prime}(t) / h^{\prime}(t)$. Then, if for $t \in J=\left[s_{1}, s_{2}\right], P^{\prime \prime}$ is of constant sign, $h^{\prime}(t) \neq 0$ and $G(t)$ is such that $\operatorname{Re} G(t) \leqq \beta t^{q} / 2(\beta>0)$ and,$\left.G^{\prime}(t)|\leqq C| t\right|^{q-1}$, there is a constant $M$ depending only on $C, \beta$ and $q$ such that

$$
\begin{aligned}
I & \equiv\left|\int_{J} \exp [i h(t)+G(t)] d t\right| \\
& \leqq M|a|^{-1} \max \left[\max _{J}|g(t)-1|,\left|g\left(s_{1}\right)\right|,\left|g\left(s_{2}\right)\right|\right] .
\end{aligned}
$$

Proof. Integration by parts yields

$$
\begin{aligned}
I \leqq & \left|\exp [i h(t)+G(t)] / h^{\prime}(t)\right| \begin{array}{l}
s_{2} \\
s_{1}
\end{array}|+| \int_{J} \exp [i h(t)+G(t)]\left(G^{\prime}(t) / h^{\prime}(t)\right) d t \mid \\
& +\left|\int_{J} \exp [i h(t)+G(t)]\left[h^{\prime \prime}(t) /\left(h^{\prime}(t)\right)^{2}\right] d t\right|=I_{1}+I_{2}+I_{3} .
\end{aligned}
$$

We have

$$
I_{1} \leqq|a|^{-1} \max _{J}\left|a / h^{\prime}(t)\right|=|a|^{-1} \max _{J}|g(t)-1|
$$

since $|\exp G(t)| \leqq \exp \left[-\beta t^{q} / 2\right]<1$.

$$
\begin{aligned}
I_{2} & \leqq \max _{J}\left|1 / h^{\prime}(t)\right| \int_{-\infty}^{\infty} \exp \left(-\frac{1}{2} \beta t^{q}\right) c|t|^{q-1} d t \\
& \leqq M_{1}|a|^{-1} \max _{J}|g(t)-1|
\end{aligned}
$$

and

$$
\begin{aligned}
I_{3} & \leqq \int_{J}\left(\left|h^{\prime \prime}(t)\right| /\left|h^{\prime}(t)\right|^{2}\right) d t \\
& =|a|^{-1} \int_{J}\left|g^{\prime}(t)\right| d t=|a|^{-1}\left|g\left(s_{2}\right)-g\left(s_{1}\right)\right|
\end{aligned}
$$

since $g^{\prime}(t)$ does not change sign. The result follows.

LEMMA 4. Let $\left(g_{n}(x)\right)$ be a sequence of real valued function on an interval $[a, b]$ such that 
(a) $g_{n}^{\prime}$ is continuous, for each $n$.

(b) $\lim _{n \rightarrow \infty} g_{n}^{\prime}(x)=g^{\prime}(x)$ uniformly

(c) $\lim _{n \rightarrow \infty} g_{n}(a)=g(a)$

(d) $g^{\prime}(x) \geqq \delta>0$.

Then, if $f(x)$ is continuous on $[a, b]$,

$$
\lim _{n \rightarrow \infty} \int_{a}^{b} f(x)\left|\cos \left(n^{\prime \prime} g_{n}(x)+\theta\right)\right| d x=\frac{2}{\pi} \int_{a}^{b} f(x) d x
$$

for any $\mu>0$ and any real $\theta$.

The lemma is a straightforward generalization of Exercise 118 in [8] and so the proof will not be given.

3. Proof of the theorem. The proof of our result is divided into several parts. We want to determine the asymptotic behavior of

$$
\left\|f^{n}\right\|=\sum\left|a_{n k}\right|=\sum \frac{1}{2 \pi}\left|\int_{-\pi}^{\pi} f^{n}(t) e^{-i k t} d t\right| .
$$

The essential ideas in the proof are these: depending upon the parameters $\alpha, p, q$ introduced above and $n$, there are only small ranges of values for $k$ near $n \alpha$ which are significant in the determination of the asymptotic behavior; and for these values of $k$ there are only small neighborhoods of $t=0$ in the integrals above which are of significance. Part 1 will provide an initial reduction of the expression above. Part 2 will further this reduction for the case $p \neq q$. In the remaining three parts the asymptotic constants will be obtained separately for the cases $p \neq q, p$ even; $p \neq q, p$ odd; $p=q$.

We shall omit the phrase "for $n$ sufficiently large" finitely many times in the course of the proof.

The following notation will also be used consistently:

$$
\begin{array}{cc}
c=1-(p-1) / q \quad b_{n} & =[(1-p / q) / 2+1] \log n \\
\mu=n \alpha-k \quad \gamma=(n \alpha-k) n^{-1 / q} & \\
S(n)=\left\{k: n^{c} b_{n} \leqq|\mu| \leqq n^{1+1 / q}\right\} & \\
T(n)= & \left\{k: b_{n}<|\mu|<n^{c} b_{n}\right\} \\
U(n)= & \left\{\gamma: n^{-1 / q} b_{n}<\gamma<n^{c-1 / q} b_{n}\right\} .
\end{array}
$$

We now choose $\varepsilon_{0}$ sufficiently small so that $\left|G_{2}(t)\right| \leqq \beta t^{q} / 2$, for $\mid t \leqq \varepsilon_{0}, \phi\left(r e^{i t}\right)$ is analytic for $|t| \leqq \varepsilon_{0}$ and $r$ sufficiently close to 1 , and $\left|\phi\left(r e^{i t}\right)\right| \leqq 1-\delta<1$ for $t= \pm \varepsilon_{0}$ and $r$ sufficiently near 1 , for some $\delta>0$. 


\section{PART 1}

We first show that

$$
2 \pi \sum_{-\infty}^{\infty}\left|a_{n k}\right|=\sum\left|\int_{-\varepsilon_{0}}^{\varepsilon_{0}} f^{n}(t) e^{-i k t} d t\right|+o\left(n^{(1-p / q) / 2}\right),
$$

as $n \rightarrow \infty$, where the range of summation is for $k \in T(n) \cup S(n)$. Let $|\mu|>n^{1+1 / q}$. Then for some $K>0,|k|>K n^{1+1 / q}$ and so by Lemma 1

$$
\sum_{|\mu|>n^{1+1 / q}}\left|a_{n k}\right| \leqq n C \sum_{|k|>n^{1+1 / q_{K}}} 1 / k^{2}=\mathcal{O}\left(n^{-1 / q}\right), \quad n \rightarrow \infty
$$

If we write

$$
2 \pi a_{n k}=\left(\int_{-\varepsilon_{0}}^{\varepsilon_{0}}+\int_{[-\pi, \pi] \backslash\left[-\varepsilon_{0}, \varepsilon_{0}\right]}\right) f^{n}(t) e^{-i k t} d t=a_{n k}^{(1)}+a_{n k}^{(2)},
$$

then

$$
\left|a_{n k}^{(1)}\right| \leqq \int_{-s_{0}}^{\varepsilon_{0}} \exp \left(-n \beta t^{q} / 2\right) d t=\mathcal{O}\left(n^{-1 / q}\right), \quad n \rightarrow \infty
$$

and since for all $t \in[-\pi, \pi] \backslash\left[-\varepsilon_{0}, \varepsilon_{0}\right]$ there is a $\eta>0$ such that $|f(t)| \leqq 1-\eta<1,\left|\alpha_{n k}^{(2)}\right| \leqq 2 \pi(1-\eta)^{n}$ and we obtain

$$
\sum_{|\mu| \leqq b_{n}}\left|a_{n k}^{(1)}\right|=\mathcal{O}\left(n^{-1 / q} b_{n}\right), \quad n \rightarrow \infty
$$

and

$$
\sum_{|\mu| \leqq n^{1+1 / q}}\left|a_{n k}^{(2)}\right|=\mathcal{O}\left(n^{1+1 / q}(1-\eta)^{n}\right), \quad n \rightarrow \infty .
$$

Each of these last sums is $o\left(n^{(1-p / q) / 2}\right)$ as $n \rightarrow \infty$ and so (3) follows.

We next show that

$$
\sum_{k \in S(n)}\left|a_{n k}^{(1)}\right|=o\left(n^{(1-p / q) / 2}\right)
$$

as $n \rightarrow \infty$ by using the analyticity of $f(t)$ at $t=0$ to deform the contour of integration for the function $\phi$. Indeed, $a_{n k}^{(1)}$ is the integral of $\phi^{n}(z) z^{-k-1}$ along the path $z=e^{i t},|t| \leqq \varepsilon_{0}$. We replace this contour by contours $\Gamma_{n k}$ chosen to be functions of $n, \alpha$ and $k$ in the following way: let

$$
\Gamma_{n k}=R_{n k}^{-} \cup Q_{n k} \cup R_{n k}^{+}
$$

where

$$
\begin{gathered}
Q_{n k}:|z|=\left\{\begin{array}{l}
1-n^{-c}, k \leqq n \alpha,|\arg z| \leqq \varepsilon_{0} \\
1+n^{-c}, k>n \alpha,|\arg z| \leqq \varepsilon_{0}
\end{array}\right. \\
R_{n k}^{ \pm}: \arg z= \pm \varepsilon_{0}\left\{\begin{array}{l}
1-n^{-c} \leqq|z| \leqq 1, k \leqq n \alpha \\
1 \leqq|z| \leqq 1+n^{-c}, k>n \alpha .
\end{array}\right.
\end{gathered}
$$


These paths are illustrated below.
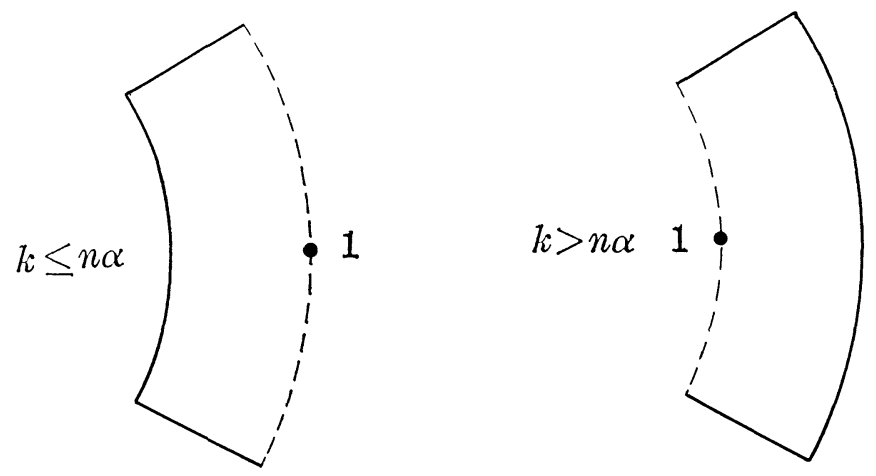

For definiteness we will assume that $\alpha>0$. The cases for $\alpha<0$ and $\alpha=0$ follow in a similar fashion. We write

$$
\sum\left|a_{n k}^{(1)}\right|<\sum_{m=1}^{3} J_{m}
$$

where

$$
J_{1}=\Sigma\left|\int_{R_{n k}^{+}}\right|, \quad J_{2}=\Sigma\left|\int_{R_{n k}^{-}}\right|, \quad J_{3}=\Sigma\left|\int_{Q_{n k}}^{-\infty}\right|
$$

the integrand in each case is $\phi^{n}(z) z^{-k-1}$ and the range of summation is for $k \in S(n)$.

We estimate each $J_{m}$ :

$$
\begin{aligned}
J_{1}, J_{2} & <\sum_{k \in S(n)} \int_{R_{n k}^{ \pm}}\left|\dot{\phi}^{n}(z) z^{-k-1}\right||d z| \\
& \leqq \sum_{k \leqq n \alpha} \int_{1-n-c}^{1}\left|\dot{\phi}\left(r e^{ \pm i \varepsilon_{0}}\right)\right|{ }^{n} r^{-k-1} d r \\
& +\sum_{k>n \alpha} \int_{1}^{1+n^{-c}}\left|\dot{\phi}\left(r e^{ \pm i \varepsilon_{0}}\right)\right|{ }^{n} r^{-k-1} d r=\sum_{1}+\sum_{2} .
\end{aligned}
$$

Now

$$
\sum_{1} \leqq 2 n^{-c}(1-\delta)^{n} r_{0}^{-1} \sum_{k \leqq n \alpha} r_{0}^{-k}, \quad r_{0}=1-n^{-c}
$$

and

$$
\sum_{k \leqq n \alpha} r_{0}^{-k}=\mathscr{O}\left[n^{c} \exp \left[\alpha n^{(p-1) / q}\right]\right], \quad n \rightarrow \infty,
$$

so

$$
\Sigma_{1}=\mathscr{O}\left[(1-\delta)^{n} \exp \left(\alpha n^{(p-1) / q}\right)\right]=o(1), \quad n \rightarrow \infty .
$$

Further, 


$$
\sum_{2} \leqq 2 n^{-c}(1-\delta)^{n^{n}} \sum_{n \alpha}^{1+1 / q} 1=o(1), \quad n \rightarrow \infty
$$

and so $J_{1}$ and $J_{2}$ are both $o\left(n^{(1-p / q) / 2}\right)$ as $n \rightarrow \infty$. To estimate $J_{3}$ we treat two cases: Then

(i) Let $\sum_{3}$ denote the sum in $J_{3}$ restricted to $k \in S(n), k>n \alpha$.

$$
\begin{aligned}
\sum_{3} & =\sum r^{n \alpha-k}\left|\int_{-\varepsilon_{0}}^{\varepsilon_{0}}\left[\left(r e^{i t}\right)^{-\alpha} \dot{\phi}\left(r e^{i t}\right)\right]^{n} e^{i(n \alpha-k) t} d t\right| \\
& \leqq \sum r^{n \alpha-k} \int_{-\varepsilon_{0}}^{\varepsilon_{0}} \exp [n \psi(r, t)] d t \\
& =O\left(n^{-1 / q}\right) \sum r^{n \alpha-k}, \quad r=1+n^{-c}
\end{aligned}
$$

by applying Lemma 2 and since

$$
\begin{gathered}
\sum_{k \in S(n), k>n \alpha} r^{n \alpha-k} \sim n^{c} \exp \left(-b_{n}\right), \\
\sum_{3}=\mathcal{O}^{\prime}\left[n^{(1-p / q) / 2-1}\right]=o\left(n^{(1-p / q) / 2}\right), \quad n \rightarrow \infty .
\end{gathered}
$$

(ii) If $\sum_{4}$ is the sum in $J_{3}$ restricted to $k<n \alpha$,

$$
\sum_{4}=\mathcal{O}\left(n^{-1 / q}\right) \sum r^{n \alpha-k}, \quad r=1-n^{-c}
$$

as $n \rightarrow \infty$. This last sum is also of order $n^{c} \exp \left(-b_{n}\right)$ and so $\sum_{4}=$ $o\left(n^{(1-p / q) / 2}\right)$ as $n \rightarrow \infty$ completing the estimate for $J_{3}$. Thus, we can write

$$
2 \pi \sum_{k=-\infty}^{\infty}\left|a_{n k}\right|=\sum_{k \in T(n)}\left|a_{n k}^{(1)}\right|+o\left(n^{(1-p / q) / 2}\right), \quad n \rightarrow \infty .
$$

\section{PART 2}

By making a simple change of variable we can write

$$
\begin{aligned}
& \sum_{i \in T^{\prime}(n)}\left|a_{n k}^{(1)}\right| \\
= & \sum_{\gamma \in U(n)} n^{-1 / q}\left[\left|\int_{-\varepsilon_{0} n^{1 / q}}^{\varepsilon_{c} n^{1 / q}} \exp \left[i \gamma t+\operatorname{inp}\left(t n^{-1 / q}\right)+n G_{1}\left(t n^{-1 / q}\right)\right] d t\right|\right. \\
& \left.+\left|\int_{-\varepsilon_{0} n^{1 / q}}^{\varepsilon_{c} n^{1 / q}} \exp \left[-i \gamma t+\operatorname{inp}\left(t n^{-1 / q}\right)+n G_{1}\left(t n^{-1 / q}\right)\right] d t\right|\right]
\end{aligned}
$$

where

$$
p(t)=b t^{p}+\sum_{k=p+1}^{q} b_{k} t^{k}
$$

If $b<0$, we can write $p(t)$ using $-|b|$ instead of $b$ and then by taking conjugates (5) can be put into the same form as above with 
$|b|$ instead of $b$. Hence, whether $b$ is positive or negative (5) can be written in the form

$$
\begin{aligned}
& \sum_{r \in U(n)} n^{-1 / q}\left[\left|\int_{-\varepsilon_{0} n^{1 / q}}^{\varepsilon_{c} n^{1 / q}} \exp \left[i h_{1}(t)+G(t)\right] d t\right|\right. \\
& \left.\quad+\left|\int_{-\varepsilon_{0} n^{1 / q}}^{\varepsilon_{0} n^{1 / q}} \exp \left[i h_{2}(t)+G(t)\right] d t\right|\right]
\end{aligned}
$$

where

$$
\begin{aligned}
& h_{1}(t)=\gamma t+n P\left(t n^{-1 / q}\right) \\
& h_{2}(t)=-\gamma t+n P\left(t n^{-1 / q}\right) \\
& P(t)=b t^{p}+\sum_{k=p+1}^{q} c_{k} t^{k}, \quad b>0 \\
& G(t)=-\beta t^{q}+n^{-1 / q} G_{3}(t)
\end{aligned}
$$

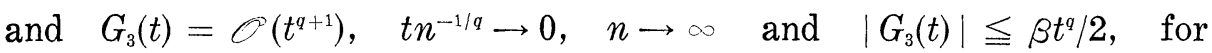
$\left|t n^{-q}\right| \leqq \varepsilon_{0}$. In what follows we will establish the existence and uniqueness of zeros of $h_{1}^{\prime}(t)$ and $h_{2}^{\prime}(t)$ in certain intervals which depend upon $n$, and then show that, after splitting off from (6) the sum of integrals in small neighborhoods of these zeros, the remainder will be $o\left(n^{(1-p / q) / 2}\right)$, as $n \rightarrow \infty$. We define

$$
\lambda_{n}=(2 / \beta)^{1 / q}\left(\log n^{(\omega)}\right)^{1 /(p-1)}
$$

where $\omega>(1-p / q) / 2$ is to be determined as follows: there is an $\omega>(1-p / q) / 2$ such that

$$
b_{n} / p b \lambda_{n}^{p-1} \leqq \delta<\frac{1}{2}
$$

Indeed, $\quad b_{n} / p b \lambda_{n}^{p-1}=(1 / p b)(\beta / 2)^{(p-1) / q}[(1-p / q) / 2+1] / \omega$. Let $V=$ $(1 / p b)(\beta / 2)^{(p-1) ! q}$. Then, if $V<1 / 2$, pick $\omega \geqq(1-p / q) / 2+1$ and if $V \geqq 1 / 2$, pick $\omega$ so large that $[(1-p / q) / 2+1] / \omega<1 / 2 V$. We establish the existence of zeros of $h_{1}^{\prime}$ and $h_{2}^{\prime}$ by use of the following inequalities: for $\varepsilon>0$ sufficiently small $P, P^{\prime}$ and $P^{\prime \prime}$ are monotone on each of $[-\varepsilon, 0]$ and $[0, \varepsilon]$ and in each of these intervals

$$
\begin{gathered}
\frac{1}{2} p b|t|^{p-1} \leqq\left|P^{\prime}(t)\right| \leqq 2 p b|t|^{p-1}, \\
\frac{1}{2} p(p-1) b|t|^{p-2} \leqq\left|P^{\prime \prime}(t)\right| \leqq 2 p(p-1) b|t|^{p-2} .
\end{gathered}
$$

For $n$ sufficiently large, $\lambda_{n} n^{-1 / q}<\varepsilon$, and then in the case of even $p$, for $t \in\left[-\lambda_{n}, 0\right]$, we have,

$$
\gamma+2 p b n^{1-p / q} t^{p-1} \leqq \gamma+n^{1-1 / q} P^{\prime}\left(t n^{-1 / q}\right) \leqq \gamma+\frac{1}{2} p b n^{1-p / q} t^{p-1}
$$


and both of these bounding polynomials have zeros in $\left[-\lambda_{n}, 0\right]$. Hence, $h_{1}^{\prime}(t)$ has a zero, say $-t_{n k}^{\prime}$ in $\left[-\lambda_{n}, 0\right]$. Furthermore, since $P^{\prime}\left(t n^{-1 / q}\right)$ is monotone there, this zero is unique and for $t \in\left[0, \lambda_{n}\right]$ we have $\left|h_{1}^{\prime}(t)\right| \geqq \gamma$. In a similar way we can show that $h_{2}^{\prime}(t)$ has a unique zero, $t_{n k}$, in $\left[0, \lambda_{n}\right]$ and $\left|h_{2}^{\prime}(t)\right| \geqq \gamma$ for $t \in\left[-\lambda_{n}, 0\right]$. If $p$ is odd, the same type of arguments yield $\left|h_{1}^{\prime}(t)\right| \geqq \gamma$ for $t \in\left[-\lambda_{n}, \lambda_{n}\right]$ and $h_{2}^{\prime}(t)$ has unique zeros in each of $\left[-\lambda_{n}, 0\right]$ and $\left[0, \lambda_{n}\right]$, say, respectively, $-\tau_{n k}$ and $t_{n k}$.

Let $t_{0}$ be a zero of $h_{1}^{\prime}(t)$ or $h_{2}^{\prime}(t)$. Then $\left|t_{0}\right|<\lambda_{n}$ and

$$
n^{1-1 / q} P^{\prime}\left(t_{0} n^{-1 / q}\right)=n^{1-p / q} p b t_{0}^{p-1}\left[1+\mathcal{O}\left(n^{-1 / q} \log n\right)\right]
$$

since $\lambda_{n}=\mathcal{O}^{\prime}(\log n)$ as $n \rightarrow \infty$. Thus,

$$
\left|t_{0}\right|=\left(\gamma / n^{1-p / q} p b\right)^{1 /(p-1)}\left(1+\mathcal{O}\left(n^{-1 / q} \log n\right)\right)
$$

as $n \rightarrow \infty$ from which it follows that

$$
\lim _{n \rightarrow \infty}\left[\left|t_{0}\right| /\left(\gamma / n^{1-p / q} p b\right)^{1 /(p-1)}\right]=1
$$

uniformly in $k$.

We now introduce the following intervals:

$$
\begin{aligned}
& I_{n k}=\left[t_{n k}\left(1-n^{-d}\right), t_{n k}\left(1+n^{-d}\right)\right] \\
& I_{n k}^{\prime}=\left[-t_{n k}^{\prime}\left(1+n^{-d}\right),-t_{n k}^{\prime}\left(1-n^{-d}\right)\right] \\
& I_{n k}^{\prime \prime}=\left[-\tau_{n k}\left(1+n^{-d}\right),-\tau_{n k}\left(1-n^{-d}\right)\right]
\end{aligned}
$$

for $d=7(1-p / q) / 16$. Also let $D_{1}=\left[\lambda_{n}, \varepsilon_{0} n^{1 / q}\right], \quad D_{2}=\left[-\varepsilon_{0} n^{1 / q},-\lambda_{n}\right]$, $D_{3}=\left[0, \lambda_{n}\right], D_{4}=D_{5} \backslash I_{n k}^{\prime}, D_{5}=\left[-\lambda_{n}, 0\right], D_{6}=D_{3} \backslash I_{n k}, D_{7}=D_{4} \mid I_{n k}^{\prime \prime}$. Our purpose is to show that if $p$ is even

$$
\begin{aligned}
\sum_{k \in T(n)}\left|a_{n k}^{(1)}\right|= & \sum_{r \in U(n)} n^{-1 / q}\left[\left|\int_{I_{n k}} \exp \left[i h_{2}(t)+G(t)\right] d t\right|\right. \\
& \left.+\left|\int_{I_{n k}^{\prime}} \exp \left[i h_{1}(t)+G(t)\right] d t\right|\right] \\
& +o\left(n^{(1-p / q) / 2}\right), \quad n \rightarrow \infty
\end{aligned}
$$

and if $p$ is odd

$$
\begin{aligned}
\sum\left|a_{n k}^{(1)}\right|= & \sum_{\gamma \in U(n)} n^{-1 / q}\left|\int_{I_{n k^{\prime} \cup I_{n k}^{\prime \prime}}} \exp \left[i h_{2}(t)+G(t)\right] d t\right| \\
& +o\left(n^{(1-p / q) / 2}\right), \quad n \rightarrow \infty .
\end{aligned}
$$

If we let

$$
C_{m j}=\sum_{r \in U(n)} n^{-1 / q}\left|\int_{D_{j}} \exp \left[i h_{m}(t)+G(t)\right] d t\right|
$$

$\mathrm{m}=1,2, j=1, \cdots, 7$, by using (5) we can write, for $p$ even, 


$$
\begin{aligned}
\left|\sum_{k \in T(n)}\right| a_{n k}^{(1)} \mid & -\sum_{\gamma \in U(n)} n^{-1 / q}\left[\left|\int_{I_{n k}} \exp \left[i h_{2}(t)+G(t)\right] d t\right|\right. \\
& \left.+\left|\int_{I_{n k}^{\prime}} \exp \left[i h_{1}(t)+G(t)\right] d t\right|\right] \mid \leqq \sum C_{1 j}+\sum C_{2 j}
\end{aligned}
$$

where the first sum is for $j=1,2,3,4$ and the second is for $j=1,2,5,6$ and if $p$ is odd

$$
\begin{aligned}
& \left|\sum_{k \in T(n)}\right| a_{n k}^{(1)}\left|-\sum_{\gamma \in U(n)} n^{-1 / q}\right| \int_{I_{n k} \cup I_{n k}^{\prime \prime}} \exp \left[i h_{2}(t)+G(t)\right] d t|| \\
& \leqq \sum C_{1 j}+\sum C_{2 j}
\end{aligned}
$$

where the first sum is for $1,2,3,5$ and the second is for $1,2,6,7$.

We must show that each of these $C_{i j}$ is $o\left(n^{(1-p / q) / 2}\right)$ as $n \rightarrow \infty$. First for $i=1,2$ and $j=1,2, C_{i j}$ is bounded by

$$
\sum_{r \in U(n)} n^{-1 / q} \int_{\lambda_{n}}^{\varepsilon_{C} n^{1 / q}}|\exp G(t)| d t \leqq \sum_{i \in C^{\prime}(n)} n^{-1 / q} \int_{\lambda_{n}}^{\infty} \exp \left(-\frac{1}{2} \beta t^{q}\right) d t
$$

and since

$$
\int_{L}^{\infty} \exp \left(-\eta t^{q}\right) d t \leqq C L^{1-q} \exp \left(-\eta L^{q}\right), \quad L>1
$$

for some constant $C$ and $\eta>0$, the sum above is bounded by

$$
\begin{aligned}
C \sum_{r \in U(n)} n^{-1 / q} \lambda_{n}^{1-q} \exp \left[-\left(\log n^{(\omega)}\right)^{q /(p-1)}\right] & \leqq C n^{c} b_{n} n^{-1 / q-\omega} \lambda_{n}^{1-q} \\
& =o\left(n^{(1-p / q) / 2}\right), \text { as } n \rightarrow \infty
\end{aligned}
$$

because $\omega>(1-p / q) / 2$.

In order to estimate the remaining $C_{i j}$ we apply Lemma 3 . Consider those integrals which have one limit zero and the other either $\lambda_{n}$ or $-\lambda_{n}$. We have $g(t)=n^{1-1 / q} P^{\prime}\left(t n^{-1 / q}\right) / h^{\prime}(t)$ where $h(t)$ is either $h_{1}(t)$ or $h_{2}(t)$ and then $g(0)=0$ and

$$
\left|g\left( \pm \lambda_{n}\right)\right| \leqq 1 /\left[1-\left|\gamma / n^{1-1 / q} P^{\prime}\left( \pm \lambda_{n} n^{-1 / q}\right)\right|\right] \text {. }
$$

But since $\lambda_{n} n^{-1 / q} \rightarrow 0$ as $n \rightarrow \infty$, we have by (7)

$$
\left|\gamma / n^{1-1 / q} P^{\prime}\left( \pm \lambda_{n} n^{-1 / q}\right)\right|<\left|\gamma / n^{1-p / q} \frac{1}{2} p b \lambda_{n}^{p-1}\right| \leqq 2 b_{n} / p b \lambda_{n}^{p-1} \leqq 2 \delta<1 .
$$

Thus, $\left|g\left( \pm \lambda_{n}\right)\right|$ is bounded and if $h^{\prime}$ has no zero in $\left[0, \lambda_{n}\right],\left|h^{\prime}(t)\right| \geqq \gamma$. Hence, $\max _{\left[0, \lambda_{n}\right]}\left|\gamma / h^{\prime}(t)\right| \leqq 1$ and so we have

$$
\left|\int_{0}^{\lambda_{n}} \exp [i h(t)+G(t)] d t\right| \leqq \frac{M}{\gamma}
$$

for some constant $M$. A similar estimate for the integral over the interval $\left[-\lambda_{n}, 0\right]$ holds and thus we obtain a bound of order 


$$
\sum_{\gamma \in U(n)}(1 / \gamma) n^{-1 / q}=\varnothing(\log n)=o\left(n^{(1-p / q) / 2}\right), \quad n \rightarrow \infty
$$

for $C_{13}, C_{15}$ and $C_{25}$.

Consider the integral

$$
\int_{D_{6}} \exp \left[i h_{2}(t)+G(t)\right] d t
$$

and write $\left[0, \lambda_{n}\right]=\left[0, x_{n}\right) \cup I_{n k} \cup\left(y_{n}, \lambda_{n}\right]$. We will show that the conditions of Lemma 3 are satisfied on these two outside intervals. First, we have shown above that $\left|g\left(\lambda_{n}\right)\right|$ is bounded. Further, $\max _{\left[0, x_{n}\right]} 1 /\left|h_{2}^{\prime}(t)\right|=1 /\left|h_{2}^{\prime}\left(x_{n}\right)\right|$ and

$$
\begin{aligned}
\left|h_{2}^{\prime}\left(x_{n}\right)\right| & =\left|-\gamma+n^{1-1 / q} P^{\prime}\left[t_{n k}\left(1-n^{-d}\right) n^{-1 / q}\right]\right| \\
& =\left|\sum_{k=p}^{q} k \mathrm{c}_{k} t_{n k}^{k-1} n^{1-k / q} \sum_{m=1}^{k-1}\left(\begin{array}{c}
k-1 \\
m
\end{array}\right)(-1)^{m} n^{-d m}\right|
\end{aligned}
$$

since $h_{2}^{\prime}\left(t_{n k}\right)=0$. This last sum is equal to

$$
n^{1-p / q} p(p-1) b t_{n k}^{p-1} n^{-d}\left[1+\mathcal{O}\left(n^{-1 / q} \log n\right)\right], \quad n \rightarrow \infty
$$

and since

$$
n^{1-p / q} p b t_{n k}^{p-1}=\gamma\left[1+\mathcal{O}\left(n^{-1 / q} \log n\right)\right], \quad n \rightarrow \infty
$$

$\left|h_{2}^{\prime}\left(x_{n}\right)\right| \geqq(1 / 2) \gamma n^{-d}$. By replacing $1-n^{-d}$ by $1+n^{-d}$ in the above arguments it follows that $\left|h_{2}^{\prime}\left(y_{n}\right)\right| \geqq(1 / 2) \gamma n^{-d}$. A similar calculation shows that $g\left(x_{n}\right)$ and $g\left(y_{n}\right)$ are both $\mathcal{O}\left(n^{d}\right)$ as $n \rightarrow \infty$. Thus, our integral is $\mathscr{O}\left(n^{d}\right)$ and we get by (10) that

$$
C_{26}=O\left(n^{d}\right) \sum_{\gamma \in L^{\prime}(n)}(1 / \gamma) n^{-1 / q}=o\left(n^{(1-p / q) / 2}\right)
$$

as $n \rightarrow \infty$. A similar argument applies also to $C_{14}, C_{27}$ and $C_{26}$.

\section{PART 3}

In this section we will obtain the asymptotic constant for the case when $p$ is even and different from $q$. Indeed, if we let

$$
\Sigma_{n}=\sum_{\gamma \in U(n)} n^{-1^{\prime} q}\left|\int_{I_{n k}} \exp \left[i h_{2}(t)+G(t)\right] d t\right|
$$

then

$$
\Sigma_{n} \sim \frac{1}{2} \operatorname{Ln}^{(1-p / q ! / 2}, \quad n \rightarrow \infty
$$

where 


$$
L=2 \alpha \sqrt{\pi} \int_{0}^{\infty} F(x) d x
$$

for

$$
F(x)=x^{-(p-2) / 2(p-1)} \exp \left(-\beta x^{q /(p-1)}\right)
$$

and

$$
a=(2 p b /(p-1))^{1 / 2} .
$$

For simplicity write $h_{2}=h$. Then $h^{(k)}\left(t_{n k}\right)=\mathcal{O}\left(n^{1-p / q} t_{n k}^{p-k}\right)$ as $n \rightarrow \infty$ for $k \geqq 2$ and so for $t \in I_{n k}$

$$
\left|h^{(k)}\left(t_{n k}\right)\left(t-t_{n k}\right)^{k} / k !\right| \leqq M n^{(1-p / q)(1-7 k / 16)} t_{n k}^{p},
$$

for some $M>0$. Using $t_{n k}^{p}=\mathcal{O}^{[}\left[(\log n)^{p /(p-1)}\right], \quad n \rightarrow \infty$ and Taylor's formula we have for $t \in I_{n k}$

$$
h(t)=h\left(t_{n k}\right)+\frac{1}{2} h^{\prime \prime}\left(t_{n k}\right)\left(t-t_{n k}\right)^{2}+\mathscr{O}\left[n^{-5(1-p / q) / 16}(\log n)^{2}\right]
$$

as $n \rightarrow \infty$. A simple calculation also yields

$$
G(t)=-\beta t_{n k}^{q}+C\left[(\log n)^{q} n^{-d}\right]
$$

for $t \in I_{n k}$ as $n \rightarrow \infty$ and so we can write

$$
\begin{aligned}
& \left|\int_{I_{n k}} \exp [i h(t)+G(t)] d t\right| \\
= & \exp \left(-\beta t_{n k}^{q}\right)\left|\int_{I_{n k}} \exp \left[i h^{\prime \prime}\left(t_{n k}\right)\left(t-t_{n k}\right)^{2} / 2\right]\left[1+G^{*}(t)\right] d t\right|
\end{aligned}
$$

where $G^{*}(t)=\mathcal{O}\left[(\log n)^{2} n^{-5(1-p / q) / 16}\right], \quad t \in I_{n k}$, as $n \rightarrow \infty$. A change of variable also yields

$$
\int_{I_{n k}} \exp \left[i h^{\prime \prime}\left(t_{n k}\right)\left(t-t_{n k}\right)^{2} / 2\right] d t=\left[2 / h^{\prime \prime}\left(t_{n k}\right)\right]^{1 / 2} \int_{0}^{w_{n k}} e^{i u} u^{-1 / 2} d u
$$

where $w_{n k}=(1 / 2) h^{\prime \prime}\left(t_{n k}\right) t_{n k}^{2} n^{-2 d}$.

Let $\sigma_{n k}=\mu / n^{c} p b$ and $\Delta \sigma_{n k}=1 / n^{c} p b$. Then we can write

$$
\left|\Sigma_{n} n^{-(1-p / q) / 2}-\frac{1}{2} L\right| \leqq \sum_{j=1}^{4} K_{j}
$$

where

$$
\begin{aligned}
K_{1}= & \left|\sum\right| \int_{0}^{w_{n k}} e^{i u} u^{-1 / 2} d u \mid \\
& \times\left[\exp \left(-\beta t_{n k}^{q}\right)\left(2 / h^{\prime \prime}\left(t_{n k}\right)\right)^{1 / 2} n^{-(1-p / q) / 2-1 / q}-a F\left(\sigma_{n k}\right) \Delta \sigma_{n k}\right]
\end{aligned}
$$




$$
\begin{aligned}
& K_{2}=\left|\sum a F\left(\sigma_{n k}\right) \Delta \sigma_{n k}\left[\left|\int_{0}^{w_{n k}} e^{i u} u^{-1 / 2} d u\right|-\sqrt{\pi}\right]\right|, \\
& K_{3}=\left|a \sqrt{\pi} \sum F\left(\sigma_{n k}\right) \Delta \sigma_{n k}-\frac{1}{2} L\right|
\end{aligned}
$$

and

$$
K_{4}=n^{-(1-p / q) / 2} \sum n^{-1 / q} \exp \left(-\beta t_{n k}^{q}\right)\left|\int_{I_{n k}} G^{*}(t) d t\right|
$$

where all sums are for $\gamma \in U(n)$.

To estimate $K_{4}$ we let $s_{n k}=\sigma_{n k}^{1 /(p-1)}$ and observe that

$$
\begin{aligned}
\sum_{\gamma \in U(n)} \exp \left(-\beta s_{n k}^{q}\right)= & p b n^{c} \sum_{\gamma \in U(n)} \exp \left(-\beta s_{n k}^{q}\right)\left(p b n^{c}\right)^{-1} \\
& =O\left(n^{c}\right) \int_{0}^{\infty} \exp \left[-\beta x^{q /(p-1)}\right] d x \\
& =\circlearrowleft\left(n^{c}\right), \quad n \rightarrow \infty .
\end{aligned}
$$

Then, since $t_{n k}=s_{n k}\left[1+\mathcal{O}\left(n^{-1 / q} \log n\right)\right]$ and $s_{n k}=\mathscr{O}(\log n)$ as $n \rightarrow \infty$,

$$
t_{n k}^{q}=s_{n k}^{q}+\mathscr{O}\left[n^{-1 / q}(\log n)^{q+1}\right], \quad n \rightarrow \infty
$$

and so

$$
\begin{aligned}
K_{4} & \leqq 2 n^{-(1-p / q) / 2-1^{\prime} q} \sum_{\gamma \in U^{\prime}(n)} \exp \left(-\beta s_{n k}^{q}\right) \int_{I_{n k}}\left|G^{*}(t)\right| d t \\
& =\circlearrowright\left[n^{c-5(1-p / q) / 4-1 / q}(\log n)^{3}\right]=o(1), \quad n \rightarrow \infty,
\end{aligned}
$$

since for $t \in I_{n k}, G^{*}(t)=\mathscr{O}\left[(\log n)^{2} n^{5(1-p / q) / 16}\right], n \rightarrow \infty$. To estimate $K_{3}$ we define a sequence of functions as follows: let

$$
F_{n}(x)=\left\{\begin{array}{cc}
\sum F\left(\sigma_{n k}\right) \chi_{n k}(x), x \in\left[b_{n}\left(n^{c} p b\right)^{-1}, b_{n}(p b)^{-1}\right] \\
0 & \text { elsewhere }
\end{array}\right.
$$

where $\chi_{n k}$ is the indicator function of $\left[\sigma_{n k}, \sigma_{n k-1}\right)$ and the sum is for $\gamma \in U(n)$. Then, the sum in $K_{3}$ is equal to $\int_{0}^{\infty} F_{n}(x) d x$ and

$$
K_{3} \leqq a \sqrt{\pi}\left[\int_{0}^{\varepsilon}\left(F_{n}+F\right) d x+\int_{R}^{\infty}\left(F_{n}+F\right) d x+\int_{\varepsilon}^{R}\left|F_{n}-F\right| d x\right]
$$

for $0<\varepsilon<R$. For any $\delta<0$, a straightforward calculation shows that there exist $\varepsilon$ and $R$ so that the sum of the first two integral expressions is bounded by $\delta / 2 a \sqrt{\pi}$ and since $F_{n}(x)$ converges uniformly to $F(x)$ on $[\varepsilon, R]$ there is an $n_{0}$ such that for $n>n_{0}$, the third integral is bounded by $\delta / 2 a \sqrt{\pi}$. Thus, $K_{3}=o(1)$ as $n \rightarrow \infty$. Also for $\varepsilon>0$ and some $M>0$, since $\int_{0}^{\infty} e^{i u} u^{-1 / 2} d u=\sqrt{\pi} e^{i \pi / 4}$, 


$$
\begin{aligned}
K_{2} \leqq & a \sum_{\gamma \in U(n)} F\left(\sigma_{n k}\right)\left|\int_{w_{n k}}^{\infty} e^{i u} u^{-1 / 2} d u\right| \Delta \sigma_{n k} \\
\leqq & M \sum_{\mu \leqq n c_{p b \varepsilon}} F\left(\sigma_{n k}\right) \Delta \sigma_{n k} \\
& \quad+a \sup _{i>n c p b \varepsilon}\left|\int_{w_{n k}}^{\infty} e^{i u} u^{-1 / 2} d u\right| \int_{\varepsilon}^{\infty} F_{n}(x) d x .
\end{aligned}
$$

The first of these terms is bounded by $M^{\prime} \varepsilon^{p^{\prime 2(p-1)}}$ for some constant $M^{\prime}$ and the second is bounded by

$$
M^{\prime \prime} \sup _{\mu>n c p b \varepsilon}\left|\int_{w_{n k}}^{\infty} e^{i u} u^{-1,2} d u\right|
$$

for some constant $M^{\prime \prime}$. Further, integration by parts twice gives

$$
\left|\int_{w_{n k}}^{\infty} e^{i u} u^{-1 / 2} d u\right|<2 / \sqrt{w_{n k}}
$$

and since $t_{n k}^{p}=\sigma_{n k}^{p /(p-1)}\left[1+\mathcal{O}\left(n^{-1 / q} \log n\right)\right] \geqq(1 / 2) \varepsilon^{p /(p-1)}$ for sufficiently large $n$, we have

$$
w_{n k} \geqq \frac{1}{4} n^{1-p, q} p(p-1) b \varepsilon^{p /(p-1)} n^{-2 t}=\frac{1}{4} n^{(1-p / q) / 8} p(p-1) b \varepsilon^{p /(p-1)} .
$$

Thus,

$$
\sup _{\mu>n c p b \varepsilon}\left|\int_{w_{n k}}^{\infty} e^{i u} u^{-1,2} d u\right|=\mathcal{O}\left(n^{-\{1-p / q) / 16}\right)
$$

as $n \rightarrow \infty$ and so for $\delta>0$ we can find an $\varepsilon>0$ and $n_{0}$ such that $n>n_{0}$ implies that $K_{2}<\delta$. To show that $K_{1}$ tends to zero as $n \rightarrow \infty$ we need the following fact:

Let $\Psi, \phi, \theta$ be complex valued functions of a real variable and let $\left(t_{n k}\right),\left(s_{n k}\right)$ be double sequences. If $\omega_{n} \rightarrow 0$ uniformly in $k$ as $n \rightarrow \infty$ and $\Psi\left(t_{n k}\right) / \dot{\phi}\left(s_{n k}\right)=1+\mathcal{O}\left(\omega_{n}\right), n \rightarrow \infty$ and

$$
\sum_{k}\left|\phi\left(s_{n k}\right) \theta\left(t_{n k}\right)\right|=\mathcal{O}(1), \quad n \rightarrow \infty,
$$

then,

$$
\left|\sum_{k} \Psi\left(t_{n k}\right) \theta\left(t_{n k}\right)-\sum \phi\left(s_{n k}\right) \theta\left(t_{n k}\right)\right|=\mathscr{O}\left(\omega_{n}\right), \quad n \rightarrow \infty
$$

To apply this it will be sufficient to estimate the behavior of

$$
\exp \left(-\beta t_{n k}^{q}\right)\left[h^{\prime \prime}\left(t_{n k}\right)\right]^{-1 / 2} \cdot\left[n^{1-p / q} p(p-1) b s_{n k}^{p-2}\right]^{1 / 2} \exp \left(\beta s_{n k}^{q}\right) .
$$

We have

$$
\exp \left[-\beta\left(t_{n k}^{q}-s_{n k}^{q}\right)\right]=1+\mathscr{O}\left[n^{-1 / q}(\log n)^{q+1}\right]
$$


as $n \rightarrow \infty$ and since $t_{n k}=\mathcal{O}(\log n), h^{\prime \prime}\left(t_{n k}\right)=n^{1-p^{\prime} q} p(p-1) b t_{n k}^{p-2}$. $\left[1+\mathcal{O}\left(n^{-1 / q} \log n\right)\right]$. This together with $t_{n k}^{p-2}=s_{n k}^{p-2}\left[1+\mathcal{O}\left(n^{-1 / q} \log n\right)\right]$ yields

$$
\left[n^{1-p^{\prime} q} p(p-1) b s_{n k}^{p-2}\right]^{1 / 2} /\left[h^{\prime \prime}\left(t_{n k}\right)\right]^{1 / 2}=1+\mathcal{O}\left(n^{-1 / q} \log n\right)
$$

and so (11) is of order $1+\mathcal{O}\left(n^{-1 / q}(\log n)^{q+1}\right)$ and hence $K_{1}=$ $\mathcal{O}\left[n^{-1 / q}(\log n)^{q+1}\right]=o(1)$ as $n \rightarrow \infty$. Thus, we have

$$
\sum_{\gamma \in U(n)} n^{-1 / q}\left|\int_{I_{n k}} \exp \left[h_{2}(t)+G(t)\right] d t\right|=n^{(1-p / q) / 2}\left[\frac{1}{2} L+o(1)\right],
$$$$
n \rightarrow \infty \text {. }
$$

In order to treat

$$
\sum_{r \in U(n)} n^{-1 / q}\left|\int_{I_{n k}} \exp \left[i h_{1}(t)+G(t)\right] d t\right|
$$

we set $u=-t$ and notice that $h_{1}(-t)$ and $G(-t)$ are of the same form respectively as $h_{2}(t)$ and $G(t)$ since both $p$ ane $q$ are even; therefore, by precisely the same argument

$$
\sum_{r \in U(n)} n^{-1 / q}\left|\int_{I_{n k}} \exp \left[i h_{1}(t)+G(t)\right] d t\right|=n^{(1-p / q) / 2}\left[\frac{1}{2} L+o(1)\right],
$$

$$
n \rightarrow \infty \text {, }
$$

and then by combining (4), (8), (12) and (13) we obtain (a) in the statement of the theorem since by computing the integral

$$
L=2[2 p b \pi /(p-1)]^{1 / 2}[(p-1) / q](1 / \beta)^{p / 2 q} \Gamma(p / 2 q) .
$$

\section{PART 4}

We consider the case when $p$ is odd and different from $q$. As before we can write

$$
\begin{aligned}
& \int_{I_{n k}} \exp \left[i h_{2}(t)+G(t)\right] d t \\
= & \exp \left[i h_{2}\left(t_{n k}\right)-\beta t_{n k}^{q}\right]\left[2 / h_{2}^{\prime \prime}\left(t_{n k}\right)\right]^{1 / 2} \int_{0}^{\omega_{n k}} e^{i u} u^{-1 / 2} d u \\
& +\exp \left[i h_{2}\left(t_{n k}\right)-\beta t_{n k}^{q}\right] \int_{I_{n k}} G^{*}(t) d t
\end{aligned}
$$

where $G^{*}(t)=\mathcal{O}\left[n^{-5(1-p / q) / 16}(\log n)^{2}\right], t \in I_{n k}$, as $n \rightarrow \infty$. But we must also take into account this same integrand for the interval $I_{n k}^{\prime \prime}$. Let

$$
h_{3}(t)=-h_{2}(-t)=-\gamma t+n^{1-p / q} b t^{p}+n \sum_{k=p+1}^{q} c_{k}(-1)^{k+1} n^{-k / q} t^{k} .
$$

Then, a change of variable and conjugation produce 


$$
\begin{aligned}
& \int_{I_{n k}^{\prime \prime}} \exp \left[i h_{2}(t)+G(t)\right] d t=\overline{\int_{-I_{n k}^{\prime \prime}} \exp \left[i h_{3}(t)+\overline{G(-t)}\right] d t} \\
= & \exp \left[-i h_{3}\left(\tau_{n k}\right)-\beta \tau_{n k}^{q}\right]\left[2 / h_{3}^{\prime \prime}\left(\tau_{n k}\right)\right]^{1 / 2} \int_{0}^{\omega_{n k}^{\prime}} e^{-i u} u^{-1 / 2} d u \\
& +\exp \left[-i h_{3}\left(\tau_{n k}\right)-\beta \tau_{n k}^{q}\right] \int_{-I_{n k}^{\prime \prime}} G^{* *}(t) d t
\end{aligned}
$$

where

$$
G^{* *}(t)=\mathscr{O}\left(n^{-5(1-p / q) / 16}(\log n)^{2}\right), t \in-I_{n k}^{\prime \prime}, \quad n \rightarrow \infty,
$$

$\omega_{n k}^{\prime}=h_{3}^{\prime \prime}\left(\tau_{n k}\right) \tau_{n k}^{2} n^{-2 d} / 2$ and $-I_{n k}^{\prime \prime}=\left[\tau_{n k}\left(1-n^{-d}\right), \tau_{n k}\left(1+n^{-d}\right)\right]$. Let

$$
\Sigma_{n}=\sum_{r \in U(n)} n^{-1 / q}\left|\int_{I_{n k} \cup I_{n k}^{\prime \prime}} \exp \left[i h_{2}(t)+G(t)\right] d t\right| .
$$

We shall show that

$$
\Sigma_{n} \sim(2 / \pi) L n^{(1-p / q) / 2}, \text { as } n \rightarrow \infty .
$$

To do this we write

$$
\left|\sum_{n} n^{-(1-p / q) / 2}-\frac{2}{\pi} L\right| \leqq \sum_{m=5}^{13} K_{m}
$$

where $K_{5}=K_{4}, K_{7}=K_{1}$,

$$
K_{6}=n^{-(1-p / q) / 2} \sum_{r \in U(n)} n^{-1 / q} \exp \left[-\beta \tau_{n k}^{q}\right] \int_{-I_{n k}^{\prime \prime}}\left|G^{* *}(t)\right| d t,
$$

$K_{8}$ is $K_{1}$ with $t_{n k}$ replaced by $\tau_{n k}$ and $w_{n k}$ replaced by $w_{n k}^{\prime}$,

$$
\begin{aligned}
K_{9} & =\left|\sum F\left(\sigma_{n k}\right) \Delta \sigma_{n k}\right| \exp \left[i h_{2}\left(t_{n k}\right)\right] \int_{0}^{\omega_{n k}} e^{i u} u^{-1 / 2} d u \\
& +\exp \left[-i h_{3}\left(\tau_{n k}\right)\right] \int_{0}^{\omega_{n k} k} e^{-i u} u^{-1 / 2} d u\left|-\frac{2}{\pi} \cdot a \sqrt{\pi} \int_{\varepsilon}^{R} F(x) d x\right|,
\end{aligned}
$$

where the sum is for $\varepsilon n^{c} p b \leqq \mu \leqq R n^{c} p b, K_{10}$ is the sum term of $K_{9}$ with the range of summation $b_{n} \leqq \mu<\varepsilon n^{c} p b, K_{11}$ is the sum term in $K_{9}$ with the range of summation $R n^{c} p b<\mu \leqq b_{n} n^{c}$,

$$
\begin{aligned}
& K_{12}=(2 a / \sqrt{\pi}) \int_{0}^{\varepsilon} F(x) d x, \\
& K_{13}=(2 a / \sqrt{\pi}) \int_{R}^{\infty} F(x) d x
\end{aligned}
$$

and $a$ and $F(x)$ are as defined in Part 3.

Again, we must show that each $K_{m}$ is $o(1)$ as $n \rightarrow \infty . K_{6}$ is treated in the same fashion as $K_{4}, K_{8}$ as $K_{1}$. We remark that there is a constant $M$ such that 


$$
\left|\int_{0}^{Y} e^{ \pm i u} u^{-1 / 2} d u\right| \leqq M
$$

for all $Y$ so that

$$
K_{10}=\mathscr{O}\left[\int_{0}^{\varepsilon} F_{n}(x) d x\right]=o(1), \quad \varepsilon \rightarrow 0
$$

and

$$
K_{11}=\mathcal{O}\left[\int_{R}^{\infty} F_{n}(x) d x\right]=o(1), \quad \mathrm{R} \rightarrow \infty .
$$

That $K_{12}=o(1), \varepsilon \rightarrow \infty$ and $K_{13}=o(1), \quad R \rightarrow \infty$ follows easily from the definition of $F(x)$. To estimate $K_{9}$ we write

$$
\begin{gathered}
K_{9} \leqq \\
\quad a \sum_{\mu} F\left(\tau_{n k}\right)\left|\int_{0}^{\omega_{n k}} e^{i u} u^{-1 / 2} d u-e^{i \pi / 4} \sqrt{\pi}\right| \Delta \sigma_{n k} \\
+a \sum_{\mu} F\left(\sigma_{n k}\right)\left|\int_{0}^{\omega_{n k}} e^{-i u} u^{-1 / 2} d u-e^{-i \pi / 4} \sqrt{\pi}\right| \Delta \sigma_{n k} \\
\left\{\begin{array}{l}
+\left|a \sqrt{\pi} \sum_{\mu} F\left(\sigma_{n k}\right)\right| \exp \left[i h_{2}\left(t_{n k}\right)+i \pi / 4\right]+\exp \left[-i h_{3}\left(\tau_{n k}\right)-i \pi / 4\right] \mid \\
-a \sqrt{\pi} \cdot(2 / \pi) \int_{\varepsilon}^{R} F(x) d x \mid
\end{array}\right.
\end{gathered}
$$

where the sum in each of these terms is over the range $\varepsilon n^{c} p b \leqq \mu \leqq$ $R n^{c} p b$. The first and second sums above are treated in the same fashion as $K_{2}$ and both are $O\left(n^{-(1-p / q) / 16}\right), n \rightarrow \infty$. The sum in (17) can be written as

$$
a \sqrt{\pi} \sum_{\mu} F\left(\sigma_{n k}\right)\left|\cos \frac{1}{2}\left[h_{2}\left(t_{n k}\right)+h_{3}\left(\tau_{n k}\right)+\pi / 2\right]\right| \Delta \sigma_{n k} .
$$

Thus, it suffices to show that the limit of the sum in the last expression is equal to

$$
(2 / \pi) \int_{\varepsilon}^{R} F(x) d x .
$$

This will be accomplished by the following steps:

(i) For each $n \geqq n_{0}$, for some $n_{0}$, there is a function $H_{n}(x)$ such that

$$
-\frac{1}{2}\left(h_{2}\left(t_{n k}\right)+h_{3}\left(\tau_{n k}\right)\right)=n^{1-p / q} H_{n}\left(\sigma_{n k}\right) ;
$$

thus, the sum above will take the form

$$
s_{n}=\sum_{\mu} F\left(\sigma_{n k}\right)\left|\cos \left(n^{1-p / q} H_{n}\left(\sigma_{n k}\right)-\frac{1}{4} \pi\right)\right| \Delta \sigma_{n k} .
$$


(ii)

$$
\left|s_{n}-\int_{\varepsilon}^{R} F(x)\right| \cos \left(n^{1-p / q} H_{n}(x)-\frac{1}{4} \pi\right)|\mathrm{d} x| \rightarrow 0, \quad n \rightarrow \infty .
$$

(iii) The limit of the integral in ii) is precisely

$$
(2 / \pi) \int_{\varepsilon}^{R} F(x) d x
$$

After we construct the sequence $\left(H_{n}(x)\right)$ iii) will follow directly as an application of Lemma 4 . To construct the sequence $\left(H_{n}(x)\right)$ first recall that

$$
h_{2}(t)=-\gamma t+n^{1-p / q} b t^{p}+n \sum_{k=p+1}^{q} c_{k} n^{-k ! q} t^{k}
$$

and

$$
h_{3}(t)=-\gamma t+n^{1-p / q} b t^{p}+n \sum_{k=p+1}^{o} c_{k}(-1)^{k} n^{-k / q} t^{k}
$$

and that $h_{2}^{\prime}\left(t_{n k}\right)=0$ and $h_{3}^{\prime}\left(\tau_{n k}\right)=0$. Let

$$
\phi_{n}(t)=t^{p-1}+\sum_{k=p+1}^{q} k c_{k}(p b)^{-1} n^{-(k-p) / q} t^{k-1}
$$

and

$$
\psi_{n}(t)=t^{p-1}+\sum_{k=p+1}^{q} k c_{k}(p b)^{-1}(-1)^{k} n^{-(k-p) / q} t^{k-1} .
$$

Then, $t_{n k}$ and $\tau_{n k}$ are respectively the unique solutions to $n^{1-p / q} p b \phi_{n}(t)=$ $\gamma$ and $n^{1-p / q} p b \psi_{n}(t)=\gamma$ in the interval $\left[0, \lambda_{n}\right]$. That is, $\phi_{n}\left(t_{n k}\right)=\sigma_{n k}$ and $\psi_{n}\left(\tau_{n k}\right)=\sigma_{n k}$. Now, $\sigma_{n k}$ is contained in the interval $[\varepsilon, R]$ since $\varepsilon n^{c} p b \leqq \mu \leqq R n^{c} p b$. We will consider $\phi_{n}$ and $\psi_{n}$ over an interval $[r, s]$ where $r>0$. First,

$$
\dot{\phi}_{n}(t)=t^{p-1}\left(1+\mathscr{O}\left(n^{-1 / q}\right)\right)=t^{p-1}+\mathscr{O}\left(n^{-1 / q}\right)
$$

on $[r, s]$ as $n \rightarrow \infty$, and then

$$
\begin{aligned}
\phi_{n}^{\prime}(t) & =(p-1) t^{p-2}\left(1+\bigodot\left(n^{-1 / q}\right)\right) \\
& \geqq \frac{1}{2}(p-1) r^{p-2}>0
\end{aligned}
$$

for $n$ sufficiently large. Thus, $\dot{\rho}_{n}(t)$ is strictly increasing for $n$ greater than some $n_{0}$. Similarly,

$$
\psi_{n}(t)=t^{p-1}\left(1+C\left(n^{-1 / q}\right)\right)
$$

and so $\psi_{n}(t)$ is strictly increasing on $[r, s]$ and there 


$$
\phi_{n}^{-1}(x)=x^{1 /(p-1)}\left(1+\mathcal{O}\left(n^{-1 / q}\right)\right)=x^{1 /(p-1)}+\mathcal{O}\left(n^{-1 / q}\right)
$$

as $n \rightarrow \infty$. Also, $\left[\phi_{n}^{-1}(x)\right]^{\prime}=1 / \dot{\phi}_{n}^{\prime}(t)$ where $x=\phi_{n}(t)$, and so there is a constant $M$ such that $\left[\phi_{n}^{-1}(x)\right]^{\prime} \leqq M$ for $x \in\left[\phi_{n}(r), \phi_{n}(s)\right]$. Similar statements hold for $\psi_{n}^{-1}(x)$. We rewrite

$$
\begin{aligned}
& -\frac{1}{2}\left(h_{2}\left(t_{n k}\right)+h_{3}\left(\tau_{n k}\right)\right) \\
= & \frac{1}{2} n^{1-p / q}\left[p b \sigma_{n k} \dot{\phi}_{n}^{-1}\left(\sigma_{n k}\right)-b\left[\phi_{n}^{-1}\left(\sigma_{n k}\right)\right]^{p}-\sum_{k=p+1}^{q} c_{k} n^{-(k-p) / q}\left[\phi_{n}^{-1}\left(\sigma_{n k}\right)\right]^{k}\right] \\
& +\frac{1}{2} n^{1-p / q}\left[p b \sigma_{n k} \psi_{n}^{-1}\left(\sigma_{n k}\right)-b\left[\psi_{n}^{-1}\left(\sigma_{n k}\right)\right]^{p}\right. \\
& \left.-\sum_{k=p+1}^{q}(-1)^{k} c_{k} n^{-\langle k-p) / q}\left[\psi_{n}^{-1}\left(\sigma_{n k}\right)\right]^{k}\right]
\end{aligned}
$$

for $n>n_{0}$. Thus, for $n>n_{0}$ we define

$$
\begin{aligned}
H_{n}(x)= & \frac{1}{2}\left[p b x \dot{\phi}_{n}^{-1}(x)-b\left[\phi_{n}^{-1}(x)\right]^{p}-\sum_{k=p+1}^{q} c_{k} n^{-(k-p) / q}\left[\dot{\phi}_{n}^{-1}(x)\right]^{k}\right] \\
& +\frac{1}{2}\left[p b x \psi_{n}^{-1}(x)-b\left[\psi_{n}^{-1}(x)\right]^{p}-\sum_{k=p+1}^{q}(-1)^{k} c_{k} n^{-(k-p) / q}\left[\psi_{n}^{-1}(x)\right]^{k}\right]
\end{aligned}
$$

for $x \in[\varepsilon, R]$, and for $n>n_{0}$ the following conditions hold:

(a) $H_{n}(x)$ and $H_{n}^{\prime}(x)$ are continuous

(b) $\lim _{n \rightarrow \infty} H_{n}(x)=(p-1) b x^{p /(p-1)}$ and $\lim _{n \rightarrow \infty} H_{n}^{\prime}(x)=p b x^{1 /(p-1)}$ uniformly

(c) $\left|H_{n}(x)-H_{n}(y)\right| \leqq M|x-y|$ where $M$ is a constant depending on $p, b, \varepsilon$ and $R$ but independent of $n$.

If we let $H(x)=(p-1) b x^{p /(p-1)}$, then $H^{\prime}(x)$ is bounded away from 0 on $[\varepsilon, R]$ and hence the conditions of Lemma 4 are satisfied and so (iii) is proved. Let

$$
F_{n}(x)=\left\{\begin{array}{cl}
\sum_{\mu=\varepsilon n c p b}^{R n^{c} p b} F\left(\sigma_{n k}\right)\left|\cos \left(n^{1-p / q} H_{n}\left(\sigma_{n k}\right)-\frac{1}{4} \pi\right)\right| \chi_{n k}(x) \\
\text { for } \quad x \in \bigcup_{k}\left[\sigma_{n k}, \sigma_{n k-1}\right) \\
0, \quad \text { elsewhere. }
\end{array}\right.
$$

Then,

$$
s_{n}=\int_{\varepsilon}^{R} F_{n}(x) d x
$$

and we need only show that

$$
\left|F_{n}(x)-F(x)\right| \cos \left(n^{1-p / q} H_{n}(x)-\frac{1}{4} \pi\right)||
$$


tends uniformly to zero on $[\varepsilon, R]$ as $n \rightarrow \infty$ in order to prove (ii). Let $x \in[\varepsilon, R]$. Then, $x \in\left[\sigma_{n k_{0}}, \sigma_{n k_{v}-1}\right]$ and thus (18) is bounded above by

$$
\begin{aligned}
F\left(\sigma_{n k_{0}}\right) \mid \cos \left(n^{1-p / q} H_{n}\left(\sigma_{n k_{0}}\right)-\frac{1}{4} \pi\right) & -\cos \left(n^{1-p / q} H_{n}(x)-\frac{1}{4} \pi\right) \mid \\
+ & \left|F\left(\sigma_{n k_{0}}\right)-F(x)\right| .
\end{aligned}
$$

Since $F^{\prime}(x)$ is bounded on $[\varepsilon, R]$, we have $\left|F\left(\sigma_{n k_{0}}\right)-F(x)\right| \leqq$ $M\left|\sigma_{n k_{j}}-x\right| \leqq M n^{c} / p b$ for some constant $M$ and so the second term tends uniformly to zero as $n \rightarrow \infty$. Also on $[\varepsilon, R], F(x) \leqq M^{\prime}$, for some $M^{\prime}$, so that the first term is majorized by (using condition $c$ ) above)

$$
\begin{aligned}
& M^{\prime}\left|\cos \left(n^{1-p / q} H_{n}\left(\sigma_{n k_{j}}\right)-\frac{1}{4} \pi\right)-\cos \left(n^{1-p / q} H_{n}(x)-\frac{1}{4} \pi\right)\right| \\
\leqq & M^{\prime} n^{1-p / q}\left|H_{n}\left(\sigma_{n k_{0}}\right)-H_{n}(x)\right| \leqq M^{\prime \prime} n^{1-p / q}\left|\sigma_{n k_{0}}-x\right| \leqq M^{\prime \prime} \mid n^{1 / q} p b .
\end{aligned}
$$

Thus, (18) tends uniformly to zero on $[\varepsilon, R]$ and so we have shown that $K_{9}=o(1)$, as $n \rightarrow \infty$. Finally, by combining (4), (9), (15) and (16) we have the result and this completes the proof for $p$ odd.

\section{PART 5}

We now consider the last case, namely $p=q$. By (4)

$$
2 \pi \sum\left|a_{n k}\right|=\sum_{k \in T(n)}\left|a_{n k}^{(1)}\right|+o(1), \quad n \rightarrow \infty
$$

and since $p=q, f(t)=\exp \left[i \alpha t+A t^{p}+G_{2}(t)\right]$ where $R e A=-\beta$, $G_{2}(t)=\mathscr{O}\left(t^{p+1}\right), \quad t \rightarrow 0$ and $\operatorname{Re}\left[G_{2}(t)\right] \leqq(1 / 2)(\operatorname{Re} A) t^{p},|t| \leqq \varepsilon_{0}$. That is, the polynomial $p(t)$ is $(\operatorname{Im} A) t^{p}$. Thus, by a change of variable

$$
\sum\left|a_{n k}^{(1)}\right|=\sum n^{-1 / q}\left|\int_{-\delta_{v} n^{1 / q}}^{\varepsilon_{0} n^{1 / q}} \exp \left[i \gamma t+a t^{p}+G(t)\right] d t\right|
$$

where the sums are for $k \in T(n)$ and where $G(t)=n^{-1 / p} \mathcal{O}\left(t^{p+1}\right)$, $t / n^{1 / p} \rightarrow 0$, as $n \rightarrow \infty$.

Further for $|t|<\lambda_{n}$ we can write $\exp G(t)=1+G^{*}(t)$ where $G^{*}(t)=\mathscr{O}\left[n^{-1 / p}(\log n)^{p+1}\right]$ as $n \rightarrow \infty$.

If we let

$$
s_{n}=\sum n^{-1 / p}\left|\int_{-\varepsilon_{\nu} n^{1 / p}}^{\varepsilon_{c} n^{1 / p}} \exp \left[i \gamma t+A t^{p}+G(t)\right] d t\right|
$$

where the sum is for $\gamma \in U(n)$ and let

$$
F(x)=\exp \left(A t^{p}\right), \quad \hat{F}(x)=\int_{-\infty}^{\infty} F(t) \exp (i x t) d t,
$$


the Fourier transform of $F$, then

$$
s_{n}-\int_{0}^{\infty}|\hat{F}| d x=o(1), \quad n \rightarrow \infty .
$$

Indeed, we can bound (19) in absolute value above by $\sum_{m=1}^{4} L_{m}$ for

$$
\begin{aligned}
& L_{1}=\left|\sum n^{-1 / p}\right| \int_{-\infty}^{\infty} \exp \left[i \gamma t+A t^{p}\right] d t\left|-\int_{0}^{\infty}\right| \hat{F}|d x|, \\
& L_{2}=\sum n^{-1 / p}\left|\int_{D_{1} \cup D_{2}} \exp \left[i \gamma t+A t^{p}+G(t)\right] d t\right|, \\
& L_{3}=\sum n^{-1 / p}\left|\int_{D_{3} \cup D_{5}} \exp \left[i \gamma t+A t^{p}\right] G^{*}(t) d t\right|, \\
& L_{4}=\sum n^{-1 / p}\left|\int_{D} \exp \left[i \gamma t+A t^{p}\right] d t\right|,
\end{aligned}
$$

where the $D_{m}$ are defined in Part 2, $D=\left(-\infty, \lambda_{n}\right) \cup\left(\lambda_{n}, \infty\right)$ and all the sums are for $\gamma \in U(n)$. First, we remark that $L_{2}$ and $L_{4}$ are bounded above by

$$
2 \sum_{r \in \cup(n)} n^{-1 / p} \int_{\lambda_{n}}^{\infty} \exp \left(-\frac{1}{2} \beta t^{p}\right) d t
$$

which is $o(1)$ as $n \rightarrow \infty$. Next, since

$$
L_{3}=\mathscr{O}\left[b_{n} n^{-1 / p}(\log n)^{p+1}\right] \int_{-\infty}^{\infty} \exp \left(R \mathrm{e} A t^{p}\right) d t=o(1), \quad n \rightarrow \infty,
$$

it remains to estimate $L_{1}$. As before we define a sequence of approximating functions

$$
F_{n}(x)=\left\{\begin{array}{cl}
\sum_{n=b_{n}}^{n 1 / p_{b}} \mid \hat{F}\left(\mu n^{-1 / p}\right) \chi_{n k}(x), & b_{n} n^{-1 / p} \leqq x<b_{n} \\
|\hat{F}(0)| & 0 \leqq x<b_{n} n^{-1 / p} \\
0 & \text { elsewhere }
\end{array}\right.
$$

The sum in $L_{1}$ is then $\int_{0}^{\infty} F_{n}(x) d x+o(1), n \rightarrow \infty$ and so we have reduced the problem to showing that

$$
\left|\int_{0}^{\infty}\left[F_{n}(x)-|\hat{F}(x)|\right] d x\right|=o(1), \quad n \rightarrow \infty .
$$

Let $R$ be a fixed positive number to be chosen below. The expression above is bounded by

$$
\int_{0}^{R}\left|F_{n}(x)-\right| \hat{F}(x)|| d x+\int_{R}^{\infty} F_{n}(x) d x+\int_{R}^{\infty}|\hat{F}(x)| d x
$$

and by using the standard estimate: $|\hat{F}(y)| \leqq K / y^{2}, y \neq 0$, for some constant $K$, we have 


$$
\int_{R}^{\infty} F_{n}(x) d x=\sum_{\mu=n^{1 / p_{R}}}^{n^{1 / p_{3}} n}\left|\hat{F}\left(\mu n^{-1 / p}\right)\right| n^{-1 / p}<n^{1 / p} \sum_{\mu=n^{1 / p_{R}}}^{\infty} 1 / \mu^{2}<1 /(R-2),
$$

and so we can pick $R$ so large that for $\delta>0$ the sum of the last two integrals above is bounded by $2 \delta / 3$. Then, for this fixed value of $R$ there is an $n_{0}$ such that for all $n>n_{0}$, the first integral is bounded by $\delta / 3$ since $F_{n}(x)$ converges uniformly to $|\hat{F}(x)|$ on $[0, R]$.

Similarly, we can show that

$$
\lim _{n \rightarrow \infty} \sum\left|a_{n k}^{(1)}\right|=\int_{-\infty}^{0}|\hat{F}| d x
$$

where the sum is for $k \in T(n), k>n \alpha$, so that if $p=q$ we have

$$
\lim _{n \rightarrow \infty} \sum\left|a_{n k}\right|=(2 \pi)^{-1}\|\hat{F}\|_{1}
$$

and this completes the proof of the theorem.

4. Several maximum points. The results we have obtained can be extended partially to the case when $|f(t)|=1$ at several points in the interval $[-\pi, \pi]$. Assume that $f(t)$ is absolutely continuous and $f^{\prime}(t)$ is of bounded variation; $|f(t)|<1, t \neq t_{j}, f\left(t_{j}\right)=1$ and $f(t)$ is analytic at $t=t_{j}, j=1, \cdots, m$. For each of the points $t_{j}$ we can define parameters $\alpha_{j}, p_{j}, q_{j}$ corresponding to the parameters $\alpha, p, q$ defined above. We let $T_{j}(n)$ and $S_{j}(n)$ be defined by replacing $\alpha, p, q$ in the definitions of $T(n)$ and $S(n)$ by $\alpha_{j}, p_{j}$ and $q_{j}$ respectively.

Let $Q_{j}, j=1, \cdots, m$ be sufficiently small intervals centered about each of the points $t_{j}$ and set $I_{j}=\int_{Q_{j}} f^{n}(t) e^{-i k t} d t, I_{j}^{\prime}=\int_{-\pi}^{\pi} f^{n}(t) e^{-i k t} d t-I_{j}$. If we assume that $\alpha_{j} \neq \alpha_{i} ; i \neq j$, then $T_{j}(n) \cap T_{i}(n)=\dot{\phi}$ for $n$ sufficiently large and it follows by a straightforward application of the previous arguments that, for $j=1, \cdots, m$,

$$
\sum\left|I_{j}\right|=o\left(n^{\left(1-p_{j} / q_{j} / 2\right.}\right), \quad \sum\left|I_{j}^{\prime}\right|=o\left(n^{\left(1-p_{j} / q_{j} / 2\right.}\right)
$$

as $n \rightarrow \infty$, where the first sum is for $k$ in the complement of $T_{j}(n)$ and the second sum is for $k \in T_{\jmath}(n)$. Thus, we have

$$
2 \pi \sum\left|a_{n k}\right|=\sum_{j=1}^{m} \sum_{k \in T_{j}}\left|I_{j}\right|+o\left(n^{(1-s) / 2}\right), \quad n \rightarrow \infty
$$

where $s=\min _{j}\left(p_{j} / q_{j}\right)$. We can also show that $\sum_{k \in T_{j}}\left|I_{j}\right|=n^{\left(1-p_{j} / q_{j}\right) / 2}$ $\left[C_{j}+o(1)\right], n \rightarrow \infty$ for a constant $C_{j}$ depending upon the parameters associated with each of the points $t_{j}$. Thus, we obtain

$$
\lim _{n \rightarrow \infty} 2 \pi n^{-(1-s) / 2} \sum_{-\infty}^{\infty}\left|a_{n k}\right|=\sum C_{j}
$$


where the sum extends over all those $j$ such that $p_{j} / q_{j}=s$. This "additivity" does not, however, extend to the general case and, as an example by Newman [7, p. 40] shows, the asymptotic limit may fail to exist.

5. A stronger result. In our proof the condition of analyticity is used only in Part 1 to show that

$$
\sum\left|a_{n k}^{(1)}\right|=o\left(n^{(1-p / q) / 2}\right), \quad n \rightarrow \infty
$$

where the sum is for $k \in s(n)$. Here we outline a proof of this statement using only the smoothness conditions assumed in Hedstrom's paper.

We first remark that the proof of our theorem from Part 2 onward is not affected if we take $b_{n}=\tau \log n$ for any fixed $\tau \geqq$ $1+(1-p / q) / 2$. Define

$$
a_{n k}^{(3)}=\int_{\mathcal{F}_{n}} f^{n}(t) e^{-i k t} d t
$$

where

$$
\mathscr{F}_{n}=\left[-\lambda_{n}^{\prime} n^{-1 / q}, \lambda_{n}^{\prime} n^{-1 / q}\right], \quad \lambda_{n}^{\prime}=\left(\frac{2}{\beta}\right)^{1 / q}\left(\omega^{\prime} \log n\right)^{1 /(p-1)}
$$

$\omega^{\prime}>(1 / 2)(1+(p+2) / q)$. For $n$ sufficiently large

$$
\left|a_{n k}^{(1)}-a_{n k}^{(3)}\right| \leqq 2 \varepsilon_{0}\left[\exp \left[-\frac{1}{2} n \beta\left(\lambda_{n}^{\prime} n^{-1 / q}\right)\right]^{q}\right]
$$

and so

$$
\sum\left|a_{n k}^{(1)}-a_{n k}^{(3)}\right|=\mathcal{O}\left[n^{1+1 / q-\omega^{\prime}}\right]=o\left(n^{(1-p / q) / 2}\right), \quad n \rightarrow \infty
$$

where the sum is for $k \in S(n)$. In order to show that $\sum\left|a_{n k}^{(3)}\right|=$ $o\left(n^{(1-p / q) / 2}\right), n \rightarrow \infty$ we treat separately the cases $p \neq q$ and $p=q$.

In the case $p \neq q$ we fix a value for $\tau \geqq 1+(1-p / q) / 2$ in $b_{n}=\tau \log n$ so that

$$
p b\left(\lambda_{n}^{\prime}\right)^{p-1} / b_{n}<1 / 2 .
$$

A change of variable followed by an application of Lemma 3 yields (as before)

$$
\left|\int_{-\lambda_{n}^{\prime}}^{\lambda_{n}^{\prime}} \exp [i h(t)+G(t)] d t\right| \leqq \frac{M}{|\gamma|}
$$

for some constant $M$; thus 


$$
\sum_{k \in S(n)}\left|a_{n k}^{(3)}\right|=\mathcal{O}\left[\sum \frac{1}{|\gamma|} n^{-1 / q}\right]=\mathcal{O}[\log n]=o\left(n^{(1-p / q) / 2}\right), \quad n \rightarrow \infty .
$$

If $p=q, a_{n k}^{(3)}$ takes the form

$$
\int_{n}[\exp i \mu t+n g(t)] d t \text {. }
$$

Integration by parts twice, followed by majorization and use of the estimate

$$
\underset{t \in \operatorname{Var}_{n}}{\operatorname{Var}}\left[n g^{\prime}(t) e^{n g(t)}\right]=\mathcal{O}\left(n^{1 / q}\right), \quad n \rightarrow \infty
$$

yields

$$
\sum_{k \in S(n)}\left|a_{n k}^{(3)}\right|=\mathcal{O}\left(\frac{1}{\log n}\right)=o(1), \quad n \rightarrow \infty
$$

Thus,

$$
\sum\left|a_{n k}^{(1)}\right| \leqq \sum\left|a_{n k}^{(1)}-a_{n k}^{(3)}\right|+\sum\left|a_{n k}^{(3)}\right|=o\left(n^{(1-p / q) / 2}\right), \quad n \rightarrow \infty
$$

in both cases.

The author wishes to thank his doctoral advisor, Professor Bogdan Bajsanski, for many useful conversations and suggestions, and the referee for several useful suggestions.

\section{REFERENCES}

1. B. Bajsanski, Sur une classe générale de procédés de sommations du type d'EulerBorel, Acad. Serbe Sci. Publi. Inst. Math., 10 (1956), 131-152.

2. - Généralisation d'un théorème de Carlemann, Acad. Serbe Sci. Publi. Inst. Math., 12 (1958), 101-108.

3. J. Clunie and P. Vermes, Regular Sonnenschein type summability methods, Acad. Roy. Belg. Bull. Cl. Sci., (5) 45 (1959), 930-954.

4. G. W. Hedstrom, Norms of powers of absolutely convergent Fourier series, Michigan Math. J., 13 (1966), 249-259.

5. J. P. Kahane, Transformées de Fourier des functions sommables, Proceedings of the International Congress of Mathematicians, 1962, Institut Mittag-Leffler, Djursholm, 1963.

6. - Sur certaines classes de séries des Fourier absolument convergentes, J. Math. Pure Appl., (9) 35 (1956), 249-259.

7. D. J. Newman, Homomorphisms of $l_{+}$, American J. Math., 91 (1969), 37-46.

8. G. Polya and G. Szegj, Aufgaben und Lehrsätze aus der Analysis, erster band, Springer Verlag, Berlin, 1964, p. 61.

9. Whitford, Leslie E., On the boundary behavior of power series, Ph. D. dissertation, The Ohio State University, 1968.

Received September 4, 1969. 



\section{PACIFIC JOURNAL OF MATHEMATICS}

\section{EDITORS}

\author{
H. SAMElson \\ Stanford University \\ Stanford, California 94305 \\ C. R. HOBBY \\ University of Washington \\ Seattle, Washington 98105
}

J. DugundjI

Department of Mathematics University of Southern California Los Angeles, California 90007

RICHARD ARENS

University of California

Los Angeles, California 90024

\section{ASSOCIATE EDITORS}
E. F. BECKENBACH
B. H. NeUmanN
F. WOLE
K. YOSHIDA

\section{SUPPORTING INSTITUTIONS}

\author{
UNIVERSITY OF BRITISH COLUMBIA \\ CALIFORNIA INSTITUTE OF TECHNOLOGY \\ UNIVERSITY OF CALIFORNIA \\ MONTANA STATE UNIVERSITY \\ UNIVERSITY OF NEVADA \\ NEW MEXICO STATE UNIVERSITY \\ OREGON STATE UNIVERSITY \\ UNIVERSITY OF OREGON \\ OSAKA UNIVERSITY \\ UNIVERSITY OF SOUTHERN CALIFORNIA
}

\author{
STANFORD UNIVERSITY \\ UNIVERSITY OF TOKYO \\ UNIVERSITY OF UTAH \\ WASHINGTON STATE UNIVERSITY \\ UNIVERSITY OF WASHINGTON \\ * * * \\ AMERICAN MATHEMATICAL SOCIETY \\ CHEVRON RESEARCH CORPORATION \\ NAVAL WEAPONS CENTER
}

The Supporting Institutions listed above contribute to the cost of publication of this Journal, but they are not owners or publishers and have no responsibility for its content or policies.

Mathematical papers intended for publication in the Pacific Journal of Mathematics should be in typed form or offset-reproduced, (not dittoed), double spaced with large margins. Underline Greek letters in red, German in green, and script in blue. The first paragraph or two must be capable of being used separately as a synopsis of the entire paper. The editorial "we" must not be used in the synopsis, and items of the bibliography should not be cited there unless absolutely necessary, in which case they must be identified by author and Journal, rather than by item number. Manuscripts, in duplicate if possible, may be sent to any one of the four editors. Please classify according to the scheme of Math. Rev. Index to Vol. 39. All other communications to the editors should be addressed to the managing editor, Richard Arens, University of California, Los Angeles, California, 90024.

50 reprints are provided free for each article; additional copies may be obtained at cost in multiples of 50 .

The Pacific Journal of Mathematics is published monthly. Effective with Volume 16 the price per volume (3 numbers) is $\$ 8.00$; single issues, $\$ 3.00$. Special price for current issues to individual faculty members of supporting institutions and to individual members of the American Mathematical Society: $\$ 4.00$ per volume; single issues $\$ 1.50$. Back numbers are available.

Subscriptions, orders for back numbers, and changes of address should be sent to Pacific Journal of Mathematics, 103 Highland Boulevard, Berkeley, California, 94708.

PUBLISHED BY PACIFIC JOURNAL OF MATHEMATICS, A NON-PROFIT CORPORATION

Printed at Kokusai Bunken Insatsusha (International Academic Printing Co., Ltd.), 7-17, Fujimi 2-chome, Chiyoda-ku, Tokyo, Japan. 


\section{Pacific Journal of Mathematics}

\section{Vol. 37, No. $2 \quad$ February, 1971}

Charles Compton Alexander, Semi-developable spaces and quotient images of metric spaces .................................... 277

Ram Prakash Bambah and Alan C. Woods, On a problem of Danzer. . . . . . . . . 295

John A. Beekman and Ralph A. Kallman, Gaussian Markov expectations and related integral equations . ....................................

Frank Michael Cholewinski and Deborah Tepper Haimo, Inversion of the Hankel

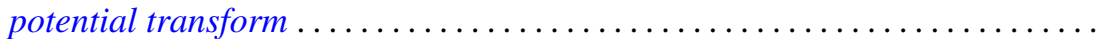

John H. E. Cohn, The diophantine equation

$$
Y(Y+1)(Y+2)(Y+3)=2 X(X+1)(X+2)(X+3) \ldots \ldots \ldots \ldots \ldots
$$

Philip C. Curtis, Jr. and Henrik Stetkaer, A factorization theorem for analytic

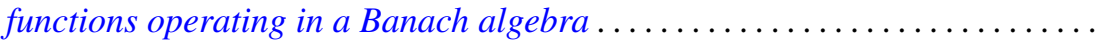

Doyle Otis Cutler and Paul F. Dubois, Generalized final rank for arbitrary limit ordinals

Keith A. Ekblaw, The functions of bounded index as a subspace of a space of entire functions

Dennis Michael Girard, The asymptotic behavior of norms of powers of

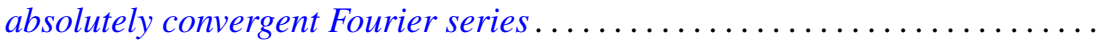

John Gregory, An approximation theory for elliptic quadratic forms on Hilbert spaces: Application to the eigenvalue problem for compact quadratic forms. 383

Paul C. Kainen, Universal coefficient theorems for generalized homology and stable cohomotopy.

Aldo Joram Lazar and James Ronald Retherford, Nuclear spaces, Schauder bases, and Choquet simplexes.

David Lowell Lovelady, Algebraic structure for a set of nonlinear integral operations

John McDonald, Compact convex sets with the equal support property . 429

Forrest Miller, Quasivector topologies

Marion Edward Moore and Arthur Steger, Some results on completability in commutative rings.

A. P. Morse, Taylor's theorem

Richard E. Phillips, Derek J. S. Robinson and James Edward Roseblade, Maximal subgroups and chief factors of certain generalized soluble groups.

Doron Ravdin, On extensions of homeomorphisms to homeomorphisms ...

John William Rosenthal, Relations not determining the structure of $\mathrm{L}$

Prem Lal Sharma, Proximity bases and subbases ........... .

Larry Smith, On ideals in $\Omega_{*}^{u}$. .

Warren R. Wogen, von Neumann algebras generated by operators similar to normal operators

R. Grant Woods, Co-absolutes of remainders of Stone-Čech 